\title{
Report on 1,000 Hour Catalyst Longevity Evaluation
}

\author{
Daniel M. Ginosar
}

June 2009

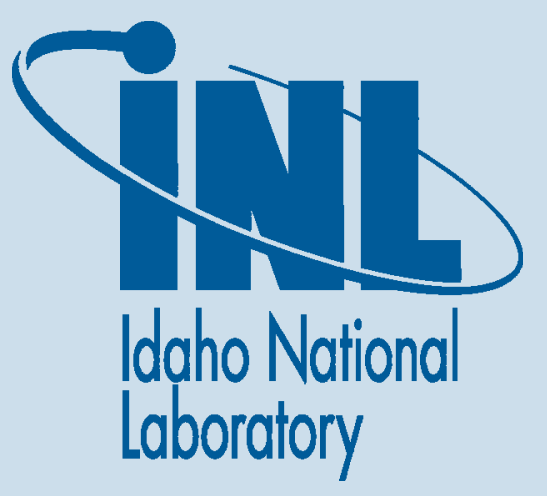

The INL is a U.S. Department of Energy National Laboratory operated by Battelle Energy Alliance. 


\section{DISCLAIMER}

This information was prepared as an account of work sponsored by an agency of the U.S. Government. Neither the U.S. Government nor any agency thereof, nor any of their employees, makes any warranty, expressed or implied, or assumes any legal liability or responsibility for the accuracy, completeness, or usefulness, of any information, apparatus, product, or process disclosed, or represents that its use would not infringe privately owned rights. References herein to any specific commercial product, process, or service by trade name, trade mark, manufacturer, or otherwise, does not necessarily constitute or imply its endorsement, recommendation, or favoring by the U.S. Government or any agency thereof. The views and opinions of authors expressed herein do not necessarily state or reflect those of the U.S. Government or any agency thereof. 


\title{
Report on 1,000 Hour Catalyst Longevity Evaluation
}

\author{
Daniel M. Ginosar
}

June 2009

Idaho National Laboratory Science and Engineering

Idaho Falls, Idaho 83415

http://www.inl.gov

Prepared for the

U.S. Department of Energy

Office of Nuclear Energy

Under DOE Idaho Operations Office

Contract DE-AC07-05ID14517 

Science and Engineering

Report on 1,000 Hour Catalyst Longevity Evaluation

INL/EXT-09-16048

June 2009
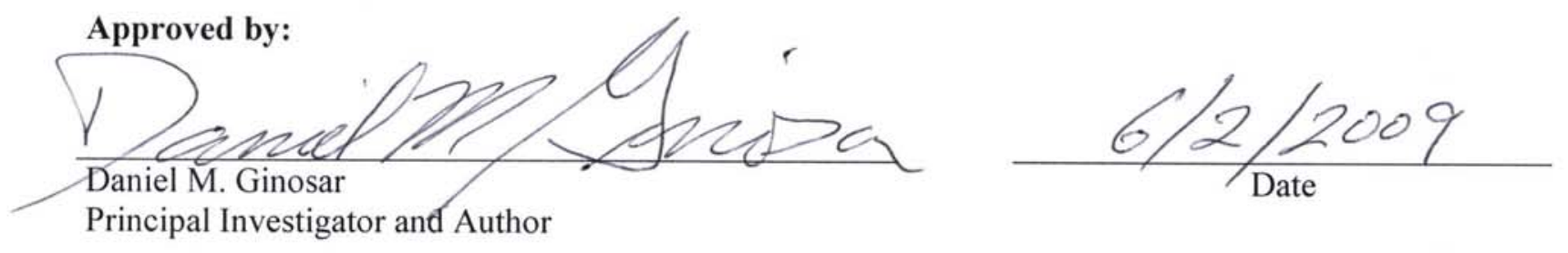

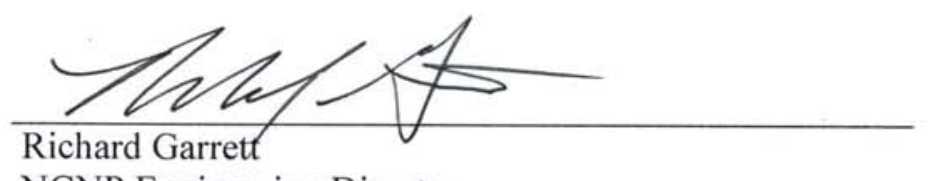

NGNP Engineering Director

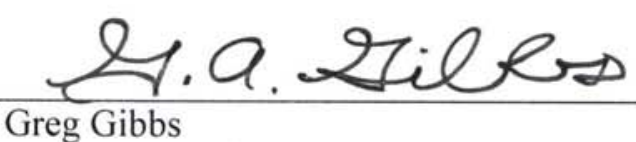

NGNP Project Director
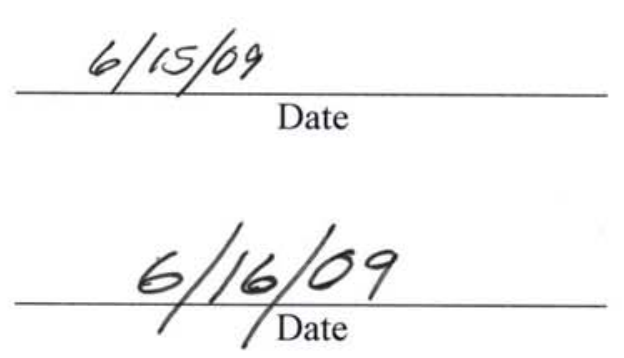



\begin{abstract}
This report presents the results of a high-pressure, catalyst longevity test for the decomposition of concentrated sulfuric acid planned for catalyst exposure of up to 1,000 hours. The reaction is used for both sulfur-iodine and hybrid sulfur hydrogen production cycles. As of April 17, 2009, the delivery date for project milestone M2NIN07TC050114, the $1 \%$ platinum/titanium-oxide $\left(\mathrm{Pt} / \mathrm{TiO}_{2}\right)$ catalyst had been in the reaction environment for 658 hours. During the first 480 hours of testing, the catalyst activity provided stable, near-equilibrium yields of $46.8 \%$ sulfur-dioxide and $22.8 \%$ oxygen. However, product yields declined at sample exposure times $>480$ hours. At 658 hours of operation, catalyst activity, based on oxygen yield, declined to $57 \%$ relative to the stable period of catalyst activity. Thus, as of April 17, this catalyst did not provide the desired stability level of $<10 \%$ degradation per 1,000 hours.

The experiment was terminated on April 27, after 792 hours, when a fitting failed and the catalyst was displaced from the reactor such that the sample could not be recovered. Product yield demonstrated a minor recovery period (experienced many times in previous experiments) from 640 to 674 hours, followed by a continued deactivation period through the end of the experiment. During the recovery period, oxygen yield increased to $17.5 \%$, a level that still represented only $76 \%$ of initial catalyst activity. Oxygen conversion at the end of the experiment was $12.5 \%$ and declining, suggesting that catalyst activity had decreased to $54 \%$ of the initial level.
\end{abstract}




\section{CONTENTS}

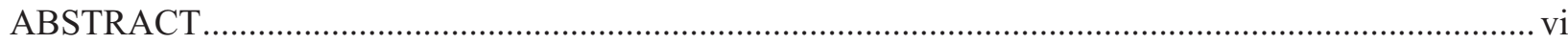

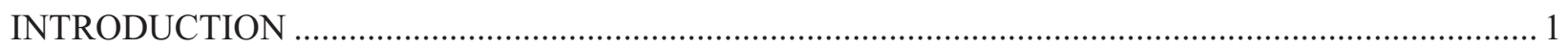

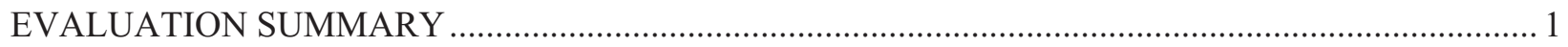

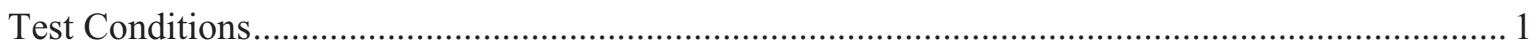

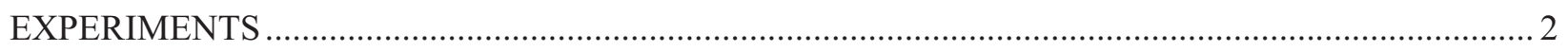

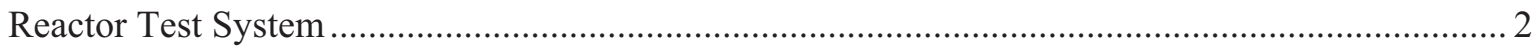

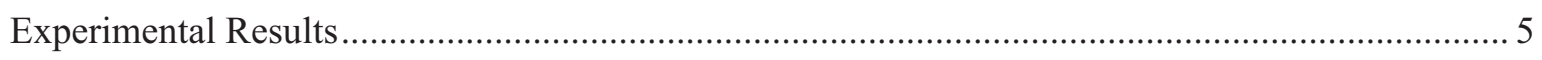

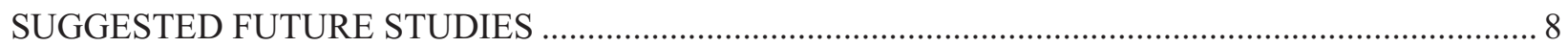

FIGURES

Figure 1. Equilibrium conversion of sulfuric acid to sulfur-dioxide and oxygen as a function of

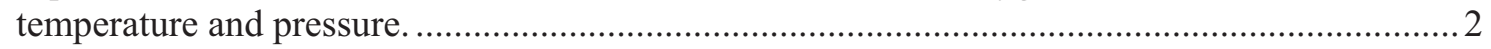

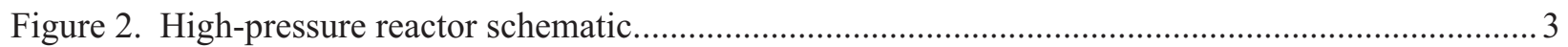

Figure 3. Ring collar on quartz tube (left). Collar tube with nylon nut, nylon/Teflon ferrule, and

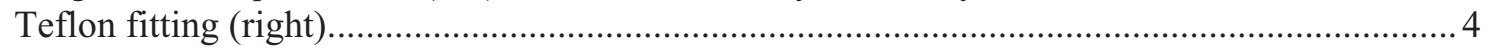

Figure 4. Reactor temperature downstream of the catalyst bed. .......................................................... 6

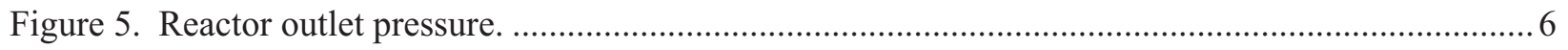

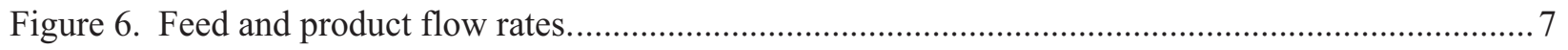

Figure 7. Product yields for sulfur-dioxide (pink) and oxygen (blue) ….............................................. 7

Figure 8. One week accelerated catalyst stability tests of $\mathrm{Pt} / \mathrm{TiO}_{2}$ catalyst with and without $0.3 \mathrm{wt} \%$ of higher melting point Pt group metals. Reaction conditions: $850^{\circ} \mathrm{C}$, atmospheric pressure, WHSV $=2,000 \mathrm{~g}$ acid/hour/g catalyst. .............................................. 8

Figure 9. Preliminary stability test of $0.3 \% \mathrm{Ru}-1 \% \mathrm{Pt} / \mathrm{TiO}_{2}$ catalyst at $825^{\circ} \mathrm{C}, 30 \mathrm{bar}$, and $\mathrm{WHSV}=18 \mathrm{~g} \mathrm{H}_{2} \mathrm{SO}_{4} /$ gram catalyst/hour. 


\section{Report on 1,000 Hour Catalyst Longevity Evaluation INTRODUCTION}

A high-pressure, catalyst longevity test for the decomposition of concentrated sulfuric acid has been completed. The reaction is used for both the sulfur-iodine (S-I) and hybrid sulfur hydrogen production cycles. The test results will support the fiscal year 2009 hydrogen technology down-selection process. The target goal is to achieve a catalyst activity degradation rate of $\leq 10 \% / 1,000$ hours.

As of April 17, 2009, the delivery date for project milestone M2NIN07TC050114, the 1\% platinum/ titanium-oxide $\left(\mathrm{Pt} / \mathrm{TiO}_{2}\right)$ catalyst had been in the reaction environment for 658 hours. During the first 480 hours of testing, the catalyst activity provided stable, near-equilibrium yields of $46.8 \%$ sulfur-dioxide $\left(\mathrm{SO}_{2}\right)$ and $22.8 \%$ oxygen $\left(\mathrm{O}_{2}\right)$. However, product yields declined at sample exposure times $>480$ hours until at 658 hours of operation, catalyst activity, based on oxygen yields, had declined to $57 \%$ relative to the stable period of catalyst activity. Thus, on the April 17 delivery date, this catalyst did not provide the desired stability level of $\leq 10 \%$ degradation per 1,000 hours.

The experiment was terminated on April 27, 2009 after 792 hours, when a fitting failed and the catalyst was displaced from the reactor such that the sample could not be recovered. Oxygen conversion at the end of the experiment was $12.5 \%$ and declining, suggesting that at that point, catalyst activity had decreased to $54 \%$ of the initial level.

In previous studies run at atmospheric pressure, two Pt catalysts stabilized with Ru and with Ir demonstrated a $300 \%$ reduction in degradation rate in one week of testing; these should be explored in the future. One preliminary stability test, run for 9 days under the same conditions as the $\mathrm{Pt} / \mathrm{TiO}_{2}$ longevity test, was performed using the $0.3 \%$ ruthenium $(\mathrm{Ru})-1 \% \mathrm{Pt} / \mathrm{TiO}_{2}$ catalyst. Over the 226 hours of operation, catalyst activity based on oxygen yields was stable, producing near equilibrium levels of sulfur-dioxide and oxygen.

\section{EVALUATION SUMMARY}

\section{Test Conditions}

After discussions and e-mails with potential stake holders in the Nuclear Hydrogen Initiative program, the following experimental conditions were chosen for the sulfuric acid decomposition catalyst longevity test:

- Catalyst reaction temperature- $825^{\circ} \mathrm{C}$

- Pressure-30 bar

- Acid concentration-40 mole $\%(78.4 \mathrm{wt} \%)$

- Weight hourly space velocity (WHSV) - $18 \mathrm{~g}$ sulfuric acid $\left(\mathrm{H}_{2} \mathrm{SO}_{4}\right) / \mathrm{g}$ catalyst/hour

- Catalyst-1 wt\% Pt supported on $\mathrm{Pt} / \mathrm{TiO}_{2}$.

The $825^{\circ} \mathrm{C}$ catalyst reaction temperature is a compromise between the desire to have a high acid decomposer temperature and thermodynamic limitations set by the Next Generation Nuclear Plant Project reactor outlet temperature for reference configurations. The 30 bar pressure level provides an equilibrium limited conversion of $46.8 \%$ at $825^{\circ} \mathrm{C}$ as shown in Figure 1, slightly less than the $48.4 \%$ conversion used in the most recent S-I process model completed by Savannah River National Laboratory, which was based on the chemical reactor condition of about $870^{\circ} \mathrm{C}$ and 85 bar. 


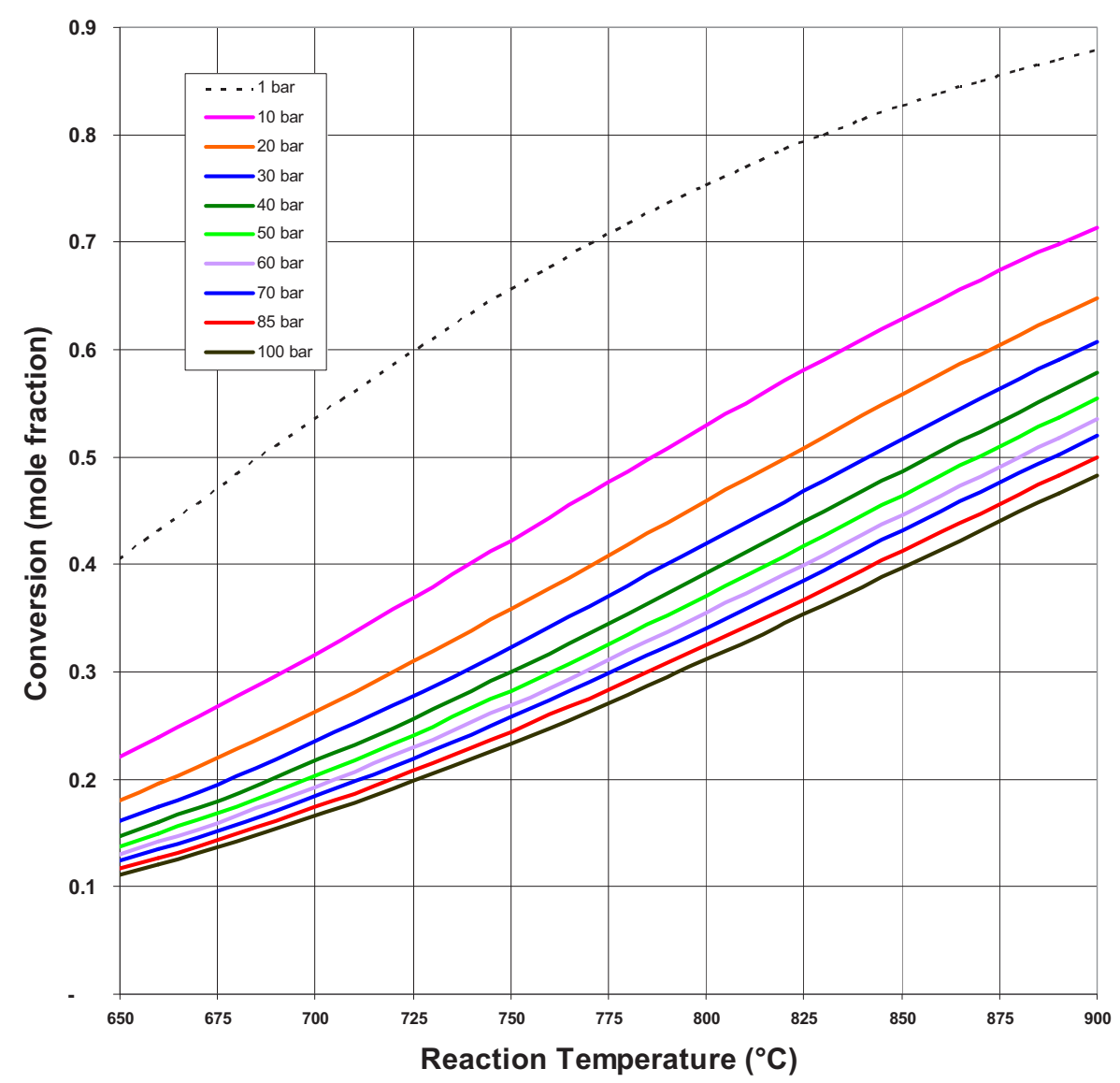

Figure 1. Equilibrium conversion of sulfuric acid to sulfur-dioxide and oxygen as a function of temperature and pressure.

The 40 mole $\% \mathrm{H}_{2} \mathrm{SO}_{4}$ concentration is based on S-I integrated laboratory scale (ILS) conditions and the recent ASPEN process model.

The WHSV of $18 \mathrm{~g} \mathrm{H}_{2} \mathrm{SO}_{4} / \mathrm{g}$ catalyst/hour is based on the highest rates run previously at Idaho National Laboratory during 1-month-long, atmospheric pressure tests.

The $1 \mathrm{wt} \% \mathrm{Pt} / \mathrm{TiO}_{2}$ catalyst was chosen because so little is known about catalyst performance at elevated pressure. Our previous accelerated deactivation tests run at atmospheric pressure showed that the addition of $0.3 \mathrm{wt} \%$ of either $\mathrm{Ru}$ or iridium ( $\mathrm{Ir}$ ) to the $1 \mathrm{wt} \% \mathrm{Pt} / \mathrm{TiO}_{2}$ catalyst decreased deactivation by a factor of 3 over 7 days of testing compared to Pt alone. However, higher pressures of oxygen may dramatically suppress the activity of Ru and Ir. Literature also suggests that higher pressures of oxygen may dramatically increase Pt sintering, and that at higher pressures, $\mathrm{TiO}_{2}, \mathrm{Pt}, \mathrm{Ru}$, or Ir may form sulfates and cause the catalyst to lose all activity.

\section{EXPERIMENTS}

\section{Reactor Test System}

The high-pressure catalyst test system design was similar to the atmospheric pressure test system previously used with some significant changes (see Figure 2). All tubing and fittings in contact with pressurized gas or acid were rated to 1,500 psi and items in contact with acid were corrosion resistant. Additionally, the materials compatible with concentrated acid up stream of the reactor 


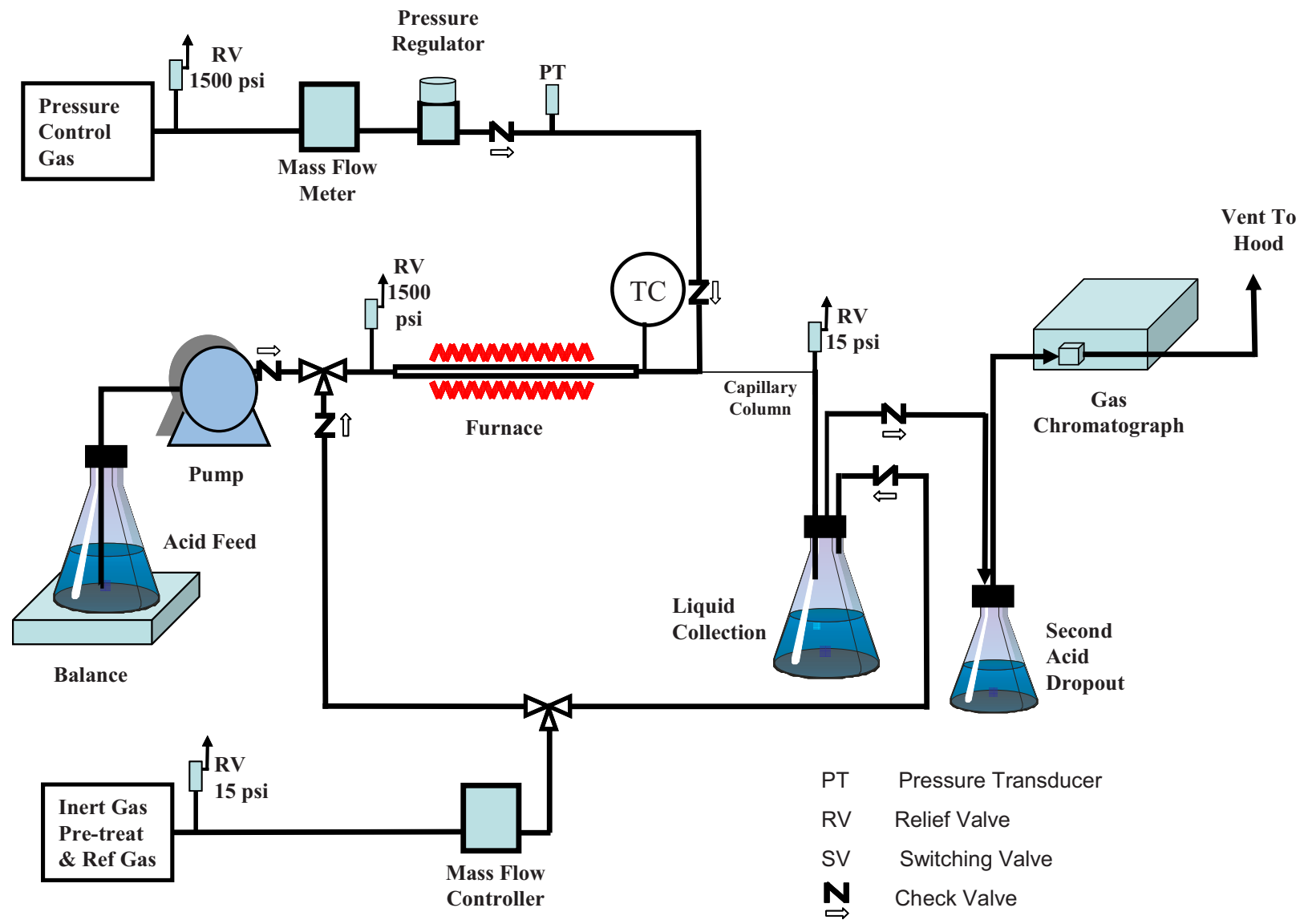

Figure 2. High-pressure reactor schematic.

were different then the materials compatible with the more dilute acid exiting the reactor. The previous system used Teflon tubing and fittings, but those parts were rated to a maximum pressure of $150 \mathrm{psi}$. The previous system employed a peristaltic pump supplied with a Teflon pump tube and had a maximum outlet pressure rating of 100 psi.

The pump was replaced with a positive displacement piston-driven pump commonly used in highperformance liquid chromatography (HPLC). All seals were replaced with acid compatible materials, and the stainless steel pump head, check valves, and fittings were coated with silicon by SilcoTeck (Bellefonte, PA). Similarly, the pressure relief valve was made from stainless steel and coated with silicon by SilcoTeck.

Cost and schedule limitations affected some of the experiment design decisions. A high-pressure syringe pump, such as the ISCO 260D (Teledyne ISCO, Lincoln, Nebraska) made of hastelloy would have been preferred, but cost and delivery schedule were outside the limits of the project. Similarly, a hastelloy pressure relief valve would have been better suited to this application, but delivery times did not match project schedule requirements.

The lower concentration of acid downstream of the reactor was significantly more corrosive then the up-stream acid. Silicon treated stainless steel was not compatible for that application and metal parts compatible with that stream were either inconel or hastelloy. During the planning phase of the project, Swagelok (Solon, $\mathrm{OH}$ ) provided information that all standard tube fittings were available in both alloys. However, when ordering the specific parts needed for this system, it was learned that many of them had delivery times between 17 and 27 weeks. Due to the short timeline for the test, these delivery times were 
unacceptable. An alternative material, Tefzel ${ }^{\circledR}$, was identified as an acceptable alternative. Tefzel ${ }^{\circledR}$ is an inert fluoropolymer that can withstand higher pressures than Teflon. Thick walled 1/16 inch OD by 0.01 inch ID tubing is rated to 4,000 psi, while thick walled $1 / 8$ inch OD Tefzel ${ }^{\circledR}$ tubing is only rated to 1,000 psi. Where ever possible, the thick walled $1 / 16$ inch OD Tefzel ${ }^{\circledR}$ tubing and fittings were used.

An additional challenge encountered in the design of the high-pressure system was the reactor material. Previous work at Sandia National Laboratory and the Idaho National Laboratory could not identify a corrosion resistant metal acceptable for that application. Two options, silica carbide and quartz, are proven to work, but compression fittings that "bite" into the tubing for both of these applications would cause cracking, an unacceptable outcome. Due to our experience with high pressure quartz windows and tubing, we chose to work with quartz.

Numerous flange/fitting designs were attempted, but proven to be too fragile. The current design uses a ring collar in the quartz tube with Teflon fittings. This design is shown in Figure 3. Since the Teflon ferrules cannot bite into the quartz tube, they slip off under pressure. The ring collar ensures that the Teflon fitting system does not slip off. The current system is an intermediate step toward a final design. The Teflon is not rated to high pressures, but seals relatively well up to 500 psi. Due to the cold flow properties of Teflon, the fittings need to be tightened every few days. We plan to work with the Teflon fitting manufacturer to develop Tefzel equivalent fittings.

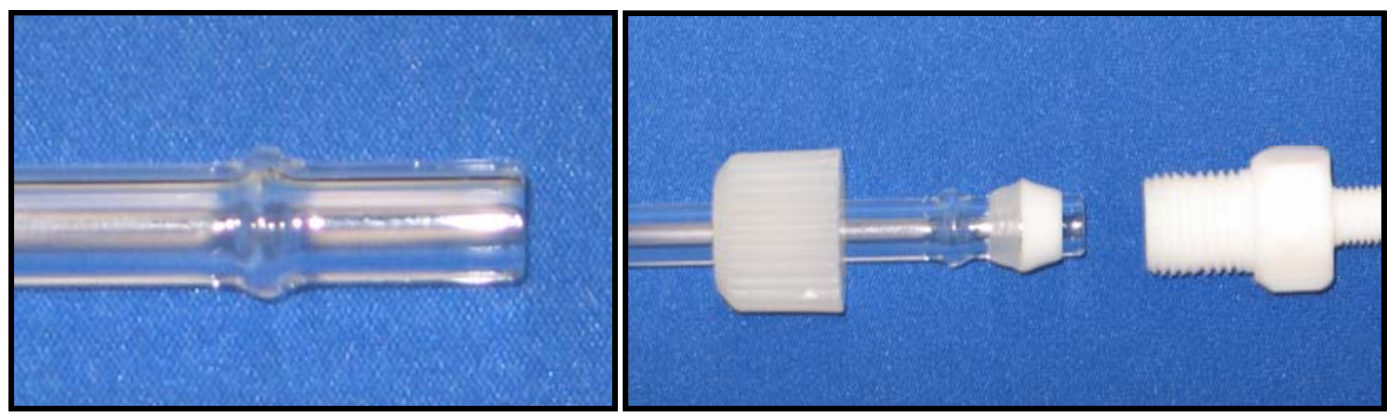

Figure 3. Ring collar on quartz tube (left). Collar tube with nylon nut, nylon/Teflon ferrule, and Teflon fitting (right).

The final system modification needed was a pressure control system. A back pressure regulator made out of hastelloy was identified, but delivery time and cost did not meet project requirements. As an alternative, a 2 meter, 150 micron fused silica capillary column was used to provide a flow restriction. Argon gas, set at the test pressure using a pressure regulator, mixed with the reactor effluent and the combined gas and liquid stream flowed through a 2 micron titanium filter frit and then through the capillary column.

The compounds exiting the column entered the first liquid collection vessel at atmospheric pressure. Production rates of oxygen and sulfur-dioxide are monitored by on-line gas chromatography. Two Agilent, two-column, micro gas cromatographs were dedicated to the experiment. Concentrations of the product gases and a reference gas (helium) are monitored to determine molar rates of the products.

The reaction takes place across a bead of catalyst located inside the quartz tube reactor. The tube reactor dimensions are $6 \mathrm{~mm}$ OD by $4 \mathrm{~mm}$ ID with a length of $90 \mathrm{~cm}$. Upstream of the catalyst bed, the reactor is filled with 20 to 40 mesh $(0.425-0.85 \mathrm{~mm})$ quartz chips to promote heat transfer and provide nucleation sites for acid boiling. The catalyst employed was supplied by Johnson Matthey with a particle size between 40 and 60 mesh $(0.250-0.425 \mathrm{~mm})$. A $2 \mathrm{~mm}$ OD quartz thermowell was inserted inside the reactor with the end located at the exit of the catalyst bed. A "X" shaped quartz spacer was welded to the thermowell to insure that the end did not touch the reactor wall, but was situated in the gas flow path. A 
narrow diameter type $\mathrm{K}$ thermocouple was place inside the thermowell and used to monitor reactor temperature.

The tube reactor was placed inside a standard single zone 18 inch tube furnace with a 1 inch inside diameter. A 6 inch long heating mantel was wrapped around the reactor tube upstream of the furnace and heated to approximately $500^{\circ} \mathrm{C}$ to provide a vaporization region. The gap between the $6 \mathrm{~mm}$ reactor tube and the 1 inch furnace opening was filled with high-temperature insulation.

Significant safety systems put in place included a mechanical pressure relief valve to protect the system from overpressure, a double barrier between the quartz tube and lab personal, and a hood flow interlock that shuts down the test system if hood flow stops.

The high-pressure longevity test was started on March 20. Gas chromatograph analysis was problematic during the first 100 hours of operation, and several recurring problems took place during the test such as plugging of the capillary column used to maintain the system back pressure, pump flow variations, and reactor plugging. These problems occurred primarily due to contamination from the corrosion of the silcosteel coated stainless steel parts. Despite claims by the silcosteel coating company, moderate corrosion took place on those parts, which included the pump head, high-pressure check valves, and safety relief valve. A moderate amount of corrosion contaminates leached into the acid and interfered with the HPLC check valve causing flow variations. Corrosion contaminates flowed into the tube reactor and caused plugging in the quartz chip vaporization zone. We speculate that some corrosion products (possibly volatile chromium salts) were carried through the reactor and deposited inside the capillary tube causing plugging problems.

Because of plugging and a few other minor problems, gas flow to the gas chromatograph was lost several times, acid flow to the reactor was lost several times, and the reactor had to be removed from the system multiple times. When the reactor was plugged and had to be removed from the system, the quartz tube was carefully split, the catalyst sample was recovered and then loaded into a new clean reactor and the new reactor with the old catalyst sample was placed back into the test system. The pump had to be replaced once because of corrosion. To represent the actual hours the catalyst sample was subjected to acid flow at the experimental conditions, the times when acid was not flowing through the catalyst bed were subtracted.

\section{Experimental Results}

Reaction temperature and pressures are shown in Figures 4 and 5. Feed and product flow rates in moles per hour are displayed in Figure 4. In all figures, the catalyst sample time on line has been adjusted to represent the actual time the catalyst sample was exposed to acid and temperature.

Figure 6 shows that the acid flow rate was highly variable. As discussed above, this variation was most likely due to corrosion products interfering with the HPLC pump check valves. These variations in feed rate resulted in variations in the rate of sulfur-dioxide and oxygen production.

Product yields, shown in Figure 7, were calculated by dividing gas production rates by acid feed rates. Because of the significant variations in the acid feed rate, large variations in the calculated yields were obtained. Four distinct regions of product yield were observed: a steady activity region between 0 and 480 hours, a declining region of activity from 480 hours to about 640 hours, a minor recovery period from 640 to 674 hours, and a continued deactivation period from 678 through the end of the experiment at 792 hours. 


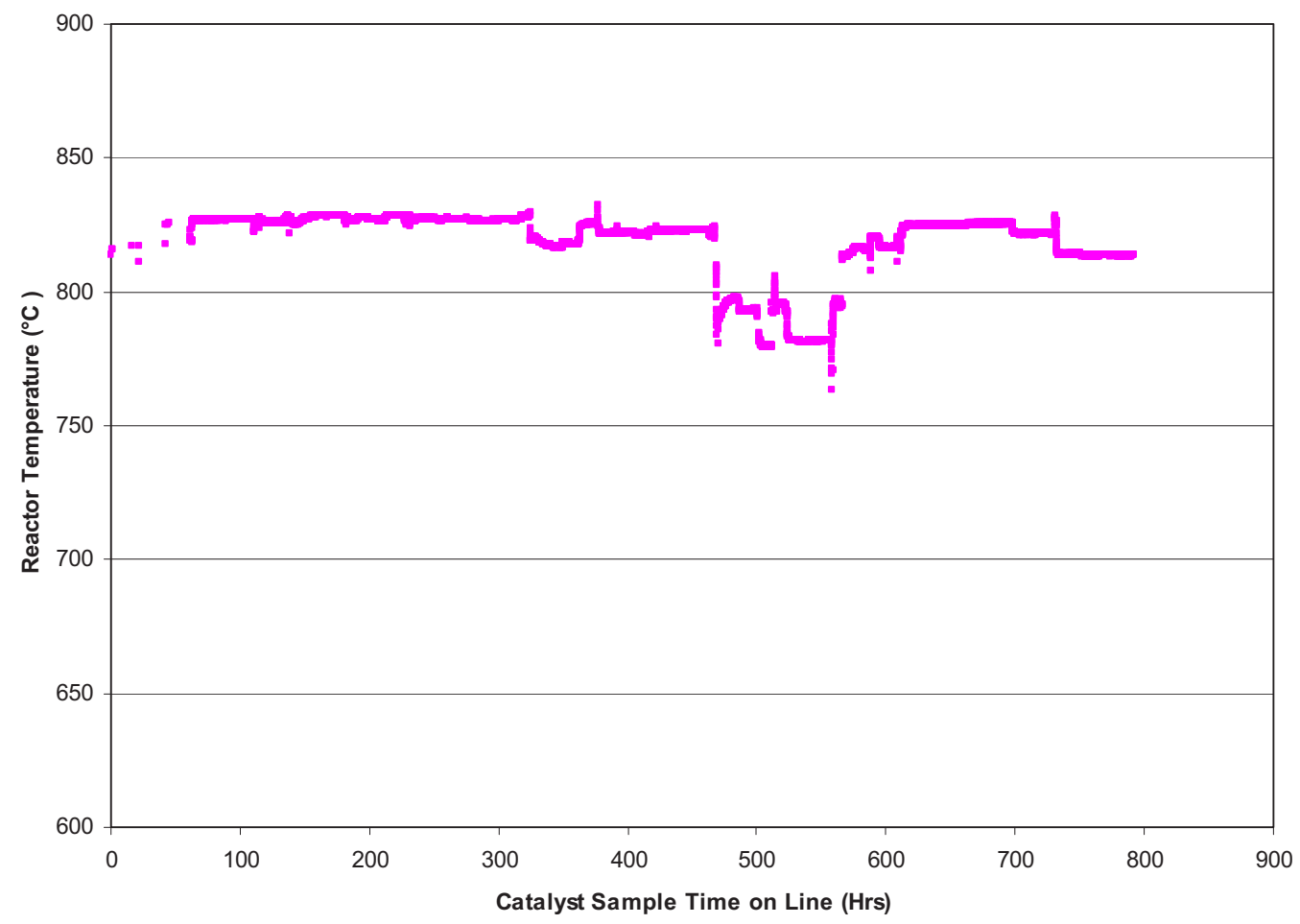

Figure 4. Reactor temperature downstream of the catalyst bed.

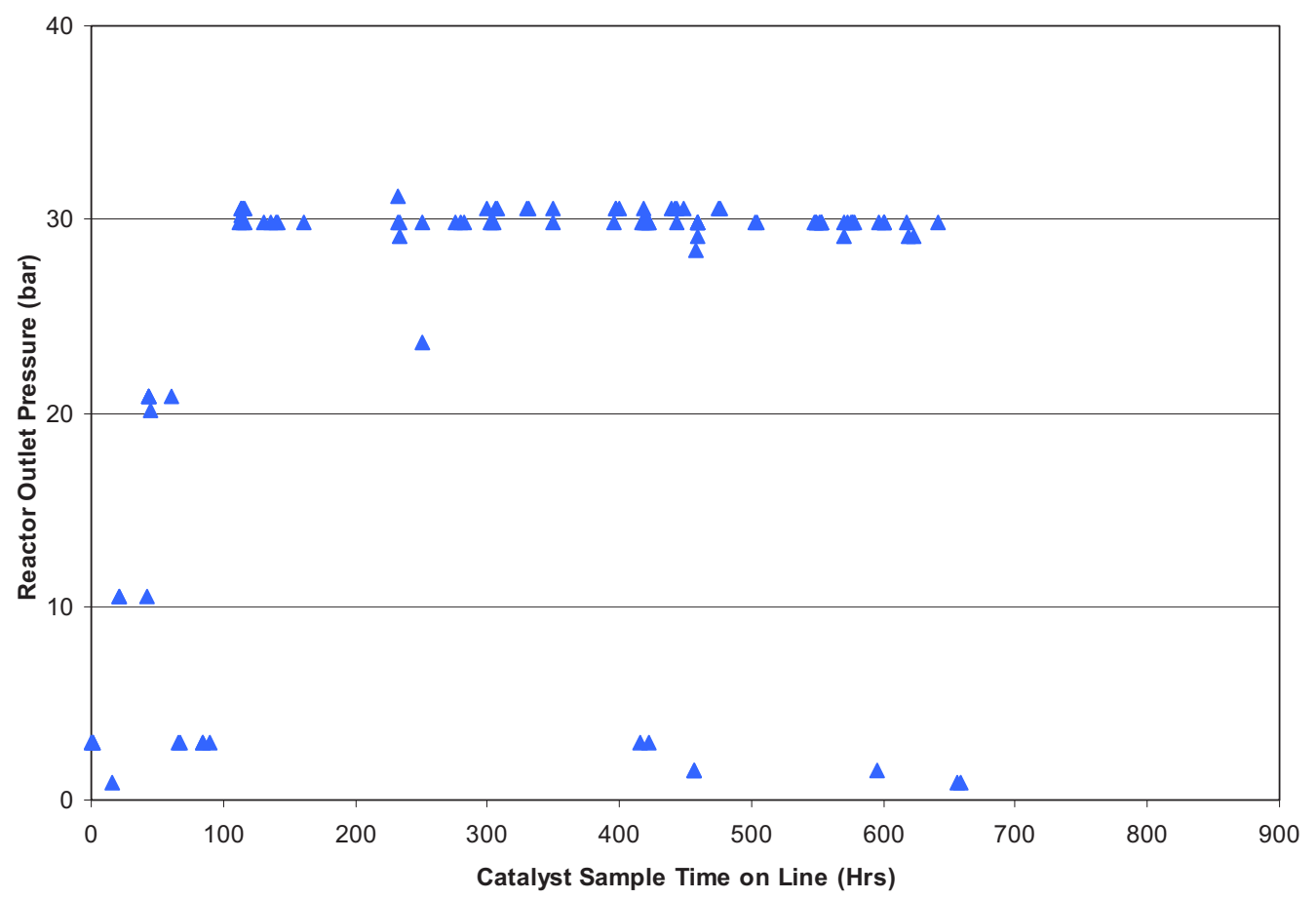

Figure 5. Reactor outlet pressure. 


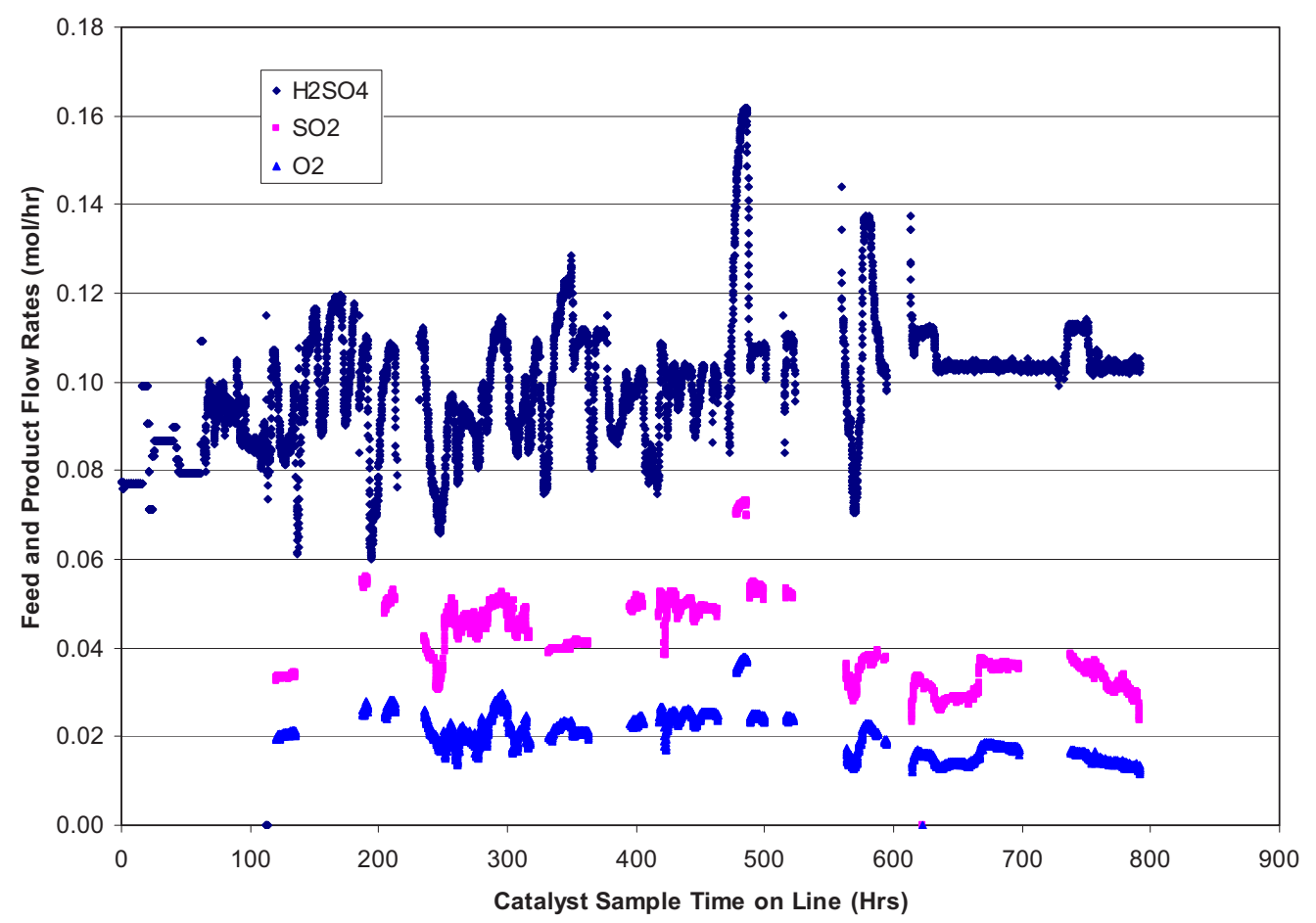

Figure 6. Feed and product flow rates.

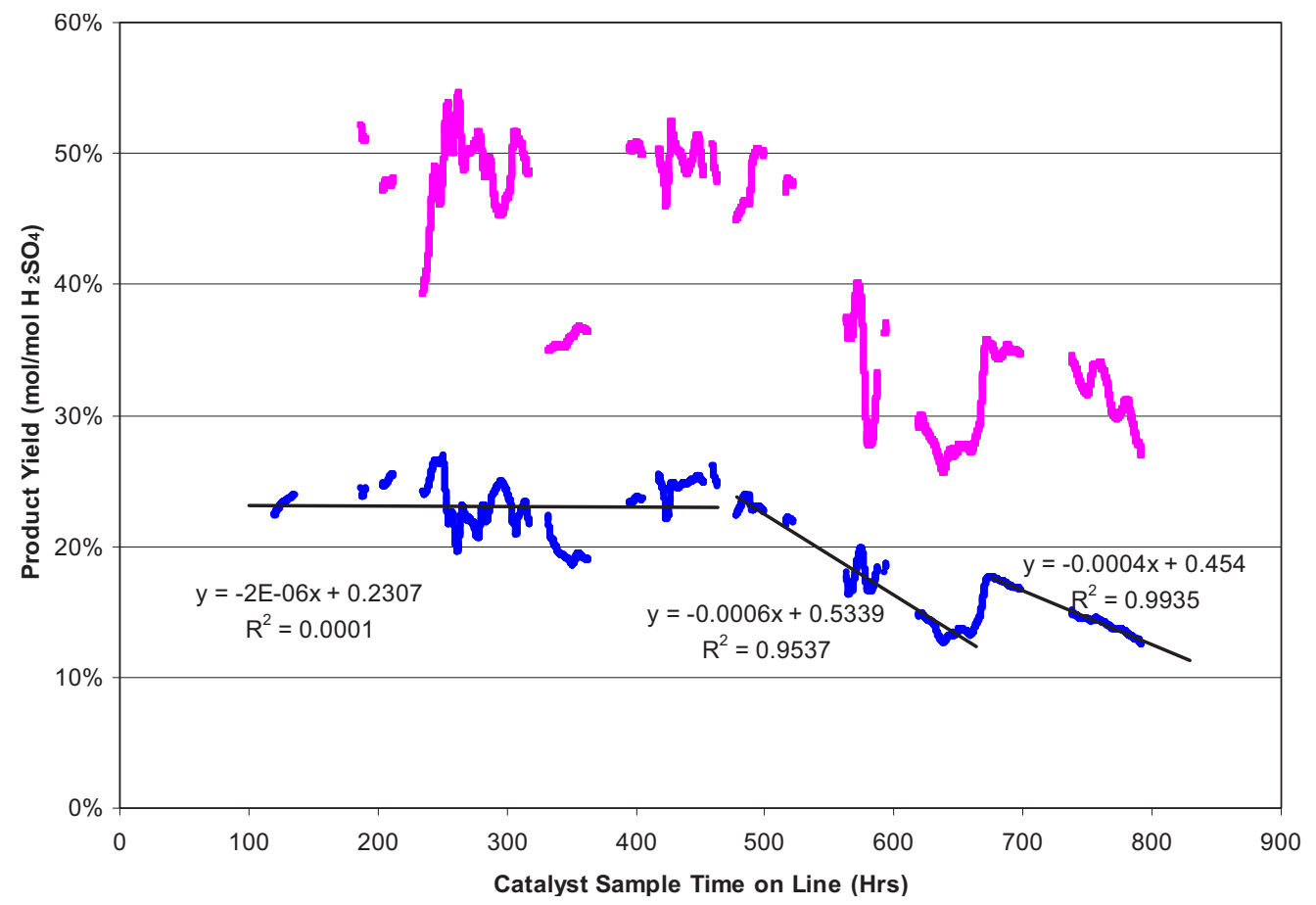

Figure 7. Product yields for sulfur-dioxide (pink) and oxygen (blue).

Between 0 and 480 hours, yields averaged $46.8 \%$ for sulfur-dioxide and $22.8 \%$ for oxygen. During the period of steady activity, product yields were in good agreement with equilibrium values of $46.8 \%$ for sulfur-dioxide and $23.0 \%$ for oxygen. Yield standard deviations were $5.5 \%$ for sulfur-dioxide and $2.0 \%$ for oxygen. On a relative basis, the standard deviation for sulfur-dioxide was greater than oxygen. This 
would be expected because sulfur-dioxide has a moderate diffusion rate through Teflon and a significant solubility in the aqueous liquid acid collection. Thus, measurements of catalyst activity are more reliable using oxygen yield values. Linear regressions of product yields in this region found that the slopes were not statistically different than zero with $\mathrm{R}^{2}$ values of 0.0015 for sulfur-dioxide and 0.0001 for oxygen.

After 480 hours, product yields declined. Using the oxygen data, catalyst activity was declining at a rate of $0.26 \%$ /hour relative to the average activity between 0 and 480 hours. At 640 hours, oxygen yield had declined to $13 \%$, or $56 \%$ of the initial level. A slight recovery period was observed between 640 and 674 hours, with oxygen yield increasing to $17.5 \%$, a level that still represented only $76 \%$ of initial catalyst activity. At 792 hours, the end of the experiment, oxygen conversion was $12.5 \%$ and declining, suggesting that catalyst activity at that point had decreased to $54 \%$ of the initial level.

The minor activity recovery period has been observed many times in previous experiments. After the brief recovery, the catalyst has always demonstrated continued deactivation. We believe that this minor recovery represents a change from one dominate rate controlling reaction mechanism to another, but the overall catalyst physical and chemical degradation processes are continuing and unchanged.

Although this loss of activity is believed to representative of the materials behavior in the reaction environment, some contamination from corrosion of the silcosteel coated stainless steel may have affected catalyst stability.

\section{SUGGESTED FUTURE STUDIES}

Previous work in this project found that adding $0.3 \mathrm{wt} \%$ of either Ru of Ir to $1 \mathrm{wt} \%$ of Pt supported on Ti decreased deactivation rates by 3 -fold in 1-week-long atmospheric pressure studies, as shown in Figure 8. It would be valuable to determine if one of these catalysts is more stable at the higher pressure operation. A preliminary stability test was run for approximately 9 days under the same conditions as the $\mathrm{Pt} / \mathrm{TiO}_{2}$ longevity test using the $0.3 \% \mathrm{Ru}-1 \% \mathrm{Pt} / \mathrm{TiO}_{2}$ catalyst. Over the 226 hours of operation, catalyst activity based on oxygen yields was stable, producing near-equilibrium levels of oxygen and sulfurdioxide as shown in Figure 9.

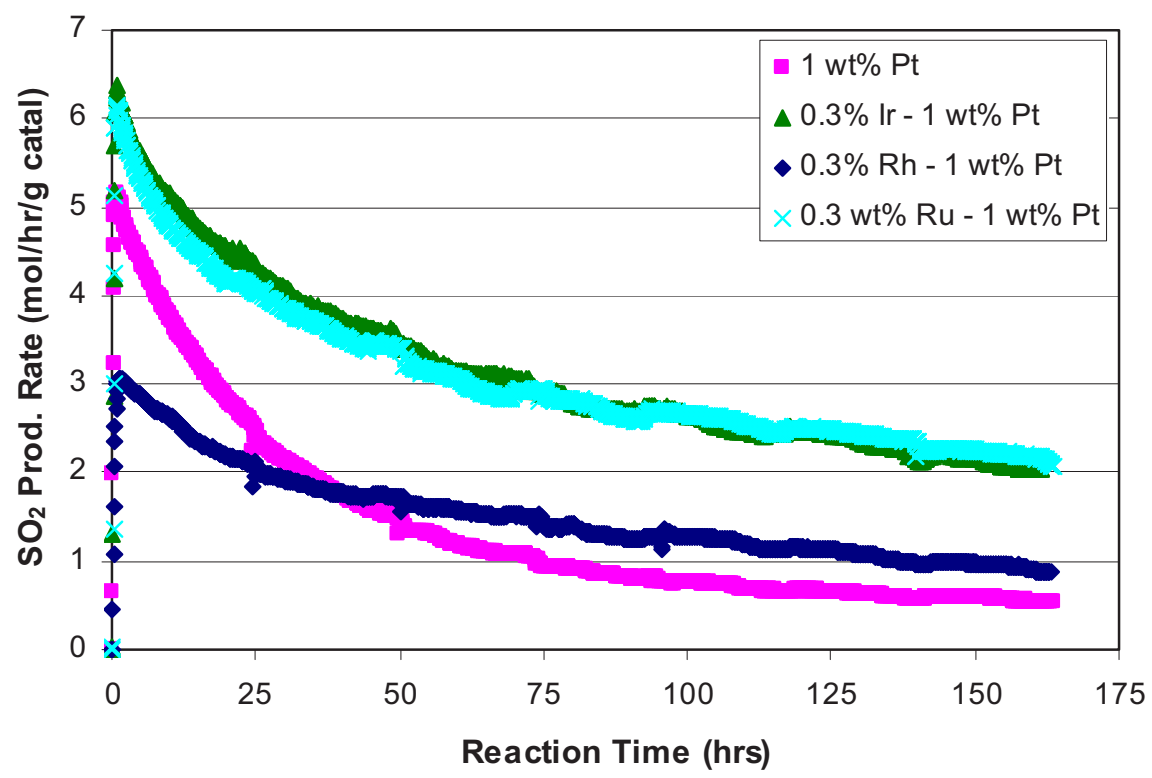

Figure 8. One week accelerated catalyst stability tests of $\mathrm{Pt} / \mathrm{TiO}_{2}$ catalyst with and without $0.3 \mathrm{wt} \%$ of higher melting point Pt group metals. Reaction conditions: $850^{\circ} \mathrm{C}$, atmospheric pressure, WHSV $=2,000 \mathrm{~g}$ acid/hour $/ \mathrm{g}$ catalyst. 


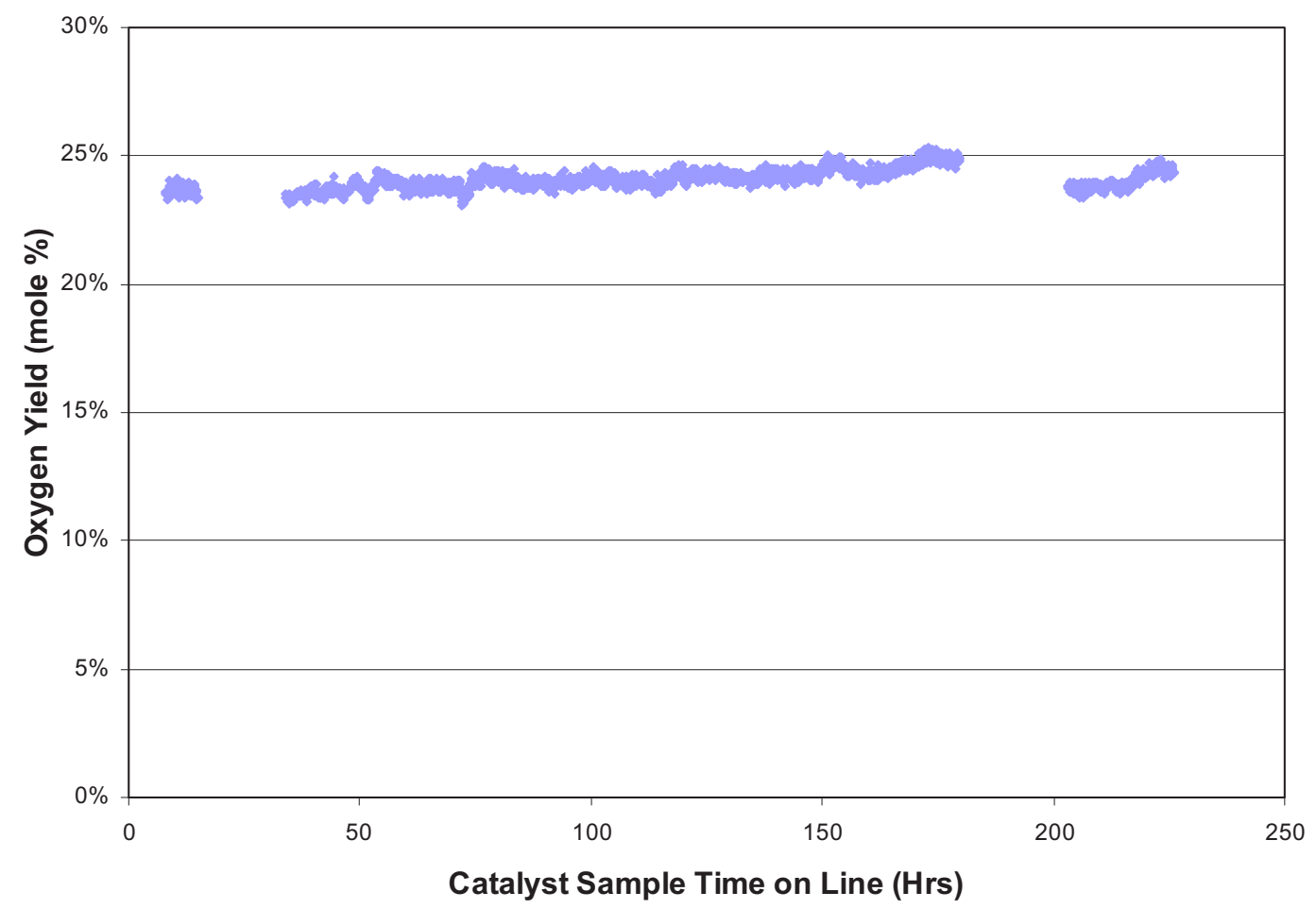

Figure 9. Preliminary stability test of $0.3 \% \mathrm{Ru}-1 \% \mathrm{Pt} / \mathrm{TiO}_{2}$ catalyst at $825^{\circ} \mathrm{C}, 30$ bar, and WHSV $=18 \mathrm{~g} \mathrm{H}_{2} \mathrm{SO}_{4} /$ gram catalyst/hour.

Although it may be desirable to examine long-term stability of this and other catalysts, system improvements should be made before additional experiments are performed. The most important changes would be to replace the silcosteel coated HPLC pump with a hastelloy high-pressure syringe pump, replace the silcosteel coated relief valve with a hastelloy model, and replace the capillary column/gas balanced pressure control system with a Teflon coated hastelloy back-pressure regulator. The INL catalyst research group has several ISCO high-pressure syringe pumps that could be retrofitted with hastelloy. It would also be useful to replace the Teflon fittings connecting the tubing to the quartz reactor with Tefzel fittings designed for the high-pressure operation.

No new potential degradation mechanisms are identified in this report (compared to the previous report dated April 17, 2009). Degradation mechanisms that may be identified in the future will be documented in the reports that summarize the future testing. 